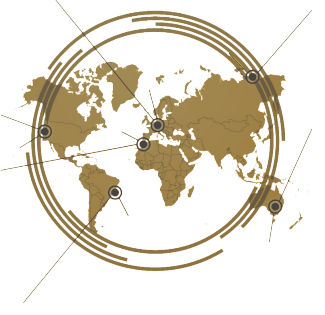

\title{
Video subtitle to teach listening skill of junior high school students
}

\author{
Mutmainnah Mustofa*, Ani Sukma Sari \\ English Education Study Program, Graduate Program of Universitas Islam Malang
}

A considerable interest on Information and Communication Technology (ICT) has been growing in the field of English language teaching within a very short period of time. Indeed, ICT is such an essential part in the respective field, in the sense that its progress allows the development of language teaching and learning process through its innovations. This study proposes using video caption as a medium to teach listening skill through integrating the use of ICT with the teaching process. An example of the innovation is the creation of teaching media supported by a software or application called. A well-known subtitle editing program, offers source tools for creating and modifying subtitle in a video. This paper presents the procedures and steps to design video subtitle by using application. Teachers can use it as a reference in designing a teaching medium using a video subtitling application which is aimed to make the students more motivated to learn English instructions. Last but not least, it is expected that learning with video caption can be an alternative and beneficial media for teaching, in particular, listening skill.

Keywords: Listening, Aegisub Application, Video Subtitle

\section{INTRODUCTION}

Most research on media and communication science in the field of English Language Teaching (ELT) tends to focus on the effects of media in teaching and on different learners. In fact, it is more crucial to pay attention to media literacy and applicability and the process of designing the media for teaching and learning. On a different note, it is also undeniable that the integration of Information and Communication Technology (ICT) into ELT has brought advantages. Sari and Sukma (2018) explained that ICT is more than capable of meeting the needs of the students through its dynamic and interactive nature, which in turn provides opportunities to direct their learning. Dang (2011) supported this statement by suggesting that this technology instantly provides information when required and it is readily accessible for educational purposes. Therefore, an ICT rich environment can help motivate and reengage students, as well as, capture their attention and develop their skills. As stated by Knezek and Christensen (2002), an integration of ICT into an English Language classroom can assist both the teachers and learners in attaining the deliberate teaching objectives since tasks will become simpler and information will be readily available and accessible.

As far as teaching receptive is particularly concerned, listening skill has been neglected despite its importance for L2 learning. However, teachers and academics should bear in mind that devoting to any of the two receptive skills may result in such a serious effect for a learner's overall proficiency in which it can affect the development of any two productive skills, namely speaking and writing skills. As an example, L2 learners are incapable of gaining the speaking and writing skills without gaining the skills of reading and listening.

Mustofa M and Sari AS (2020) Vic subtitle to teach listening skill of junior high school students.

OPEN ACCESS

${ }^{*}$ Correspondence:

Mutmainnah Mustofa Inamustofa@unisma.ac.id Accepted: 15th September 2020

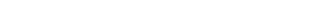


To this, Bordonaro (2014) claimed that even though listening is, or is often claimed as, a passive language skill, it can also be considered an active skill. Listening in L2 can be deemed as active skill when the listeners are given the target to succeed with complicated tasks, namely interpreting stress and intonation, and distinguishing phonemes Ghoneim (2013).

In view of the foregone, this study proposes integrating ICT with teaching by using video captions to teach listening skill. Using video in giving a learning instruction in foreign language classroom can beneficially help students perceive the message of the story more easily (Baltova, 1999). Video caption which is also well-known as same-language subtitle benefits everyone who watches video (children, adolescent, college students, and adults). This research employs a subtitling software or application called Aegisub. Aegisub is well-known as a subtitle editing program which is developed by Niels Martin Hansen and Rodrigo Monteiro. A previous study by Gernsbacher (2015) revealed that closed captioning a video can step up the comprehension of, attention to, and memory of the video as it helps learners who watch videos with the non-native language. This paper also come up with the procedures to design video caption by using Aegisub. Last but not least, it is expected that subtitled video as a teaching medium can be a beneficial alternative to teach listening skill.

\section{METHOD}

This recent study used research and development (R\&D), which, as documented by Borg et al. (2003), can be defined as one of the research designs which purpose is to develop educational product through evaluation and investigation in a real education field. To this, Latief (2015) added that "educational research \& development is a research design aimed at developing educational products, like curriculum, syllabus, text books, instructional media, modules, assessment instruments, etc."

This research was carried out at a junior high school in Mojokerto, East Java, Indonesia. The subject of this study was twenty (20) ninth grade students in this junior high school. The instrument applied was a questionnaire designed to identify the students' problems in learning English, especially the listening skill. Then, the results from a need analysis was utilized as a guidance in developing an appropriate media for teaching listening. The questionnaire contained close-ended questions in the form of Likert scale with descriptions - strongly agree, agree, disagree, strongly disagree.

To carry out the research, several procedures were applied. First, a need analysis was conducted to know the students' problem in listening. Subsequently, the writer studied the theories related to the problems and listening. Then, the media for teaching listening based on the result of the needs analysis was designed. An expert validation was obtained to know the quality of the media used. The writers then conducted a try out in order to know the appropriateness, usefulness, and effectiveness of the media for teaching listening. Lastly, the final prod- uct in the form of the media was completed.

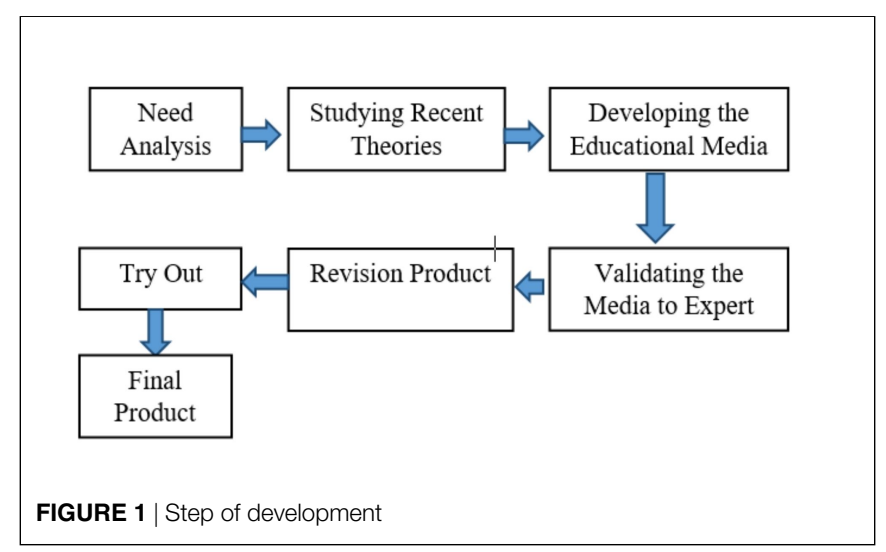

\section{RESULTS}

\section{Media Development}

The development of an ICT-based teaching media using video captions is purposed to help students in listening. For this reason, an application for editing subtitle named Aegisub is used in this research. Since interactive media is known to help the students learn listening interestingly, as confirmed by the results of a need analysis, the research chose to use an application for creating video subtitle to develop an innovative teaching media.

In the need analysis phase, there were several problems related to listening skill which students often face, such as the difficulty in understanding the fundamental content of what they are listening. Most of them stated that listening to an audio to understand the message or the conversation, which is a very common practice in a listening class, is less interesting. To this, the research intended to design a teaching medium in the form of video subtitle in order to help the students to easily understand the content of what they are listening.

This research proposed a teaching medium which employs video subtitling application. The detailed procedures to create closed caption the selected video are attached in Appendix 1. The research used a video of a traditional narrative story (fable) entitled "the Ant and the Dove". It is worth noting that, as suggested by Bruner (1991), a traditional narrative may serve as a valuable educational tool. In this sense, using subtitle can make the video more memorable. Additionally, Gernsbacher (2015) stated that video subtitle can help listener to process a spoken language easier through a written language. This allows students to comprehend the content of the video, and find out the meaning of the story. Last but not least, the research is designed to provide a guidance to compose video subtitle and implement it as an alternative media to teach listening skill.

Appendix describes the steps and the procedures in creating video subtitle using Aegisub application. It includes nineteen steps to create video subtitle using Aegisub application. One of the steps during the process is shown in Figure 2 . 


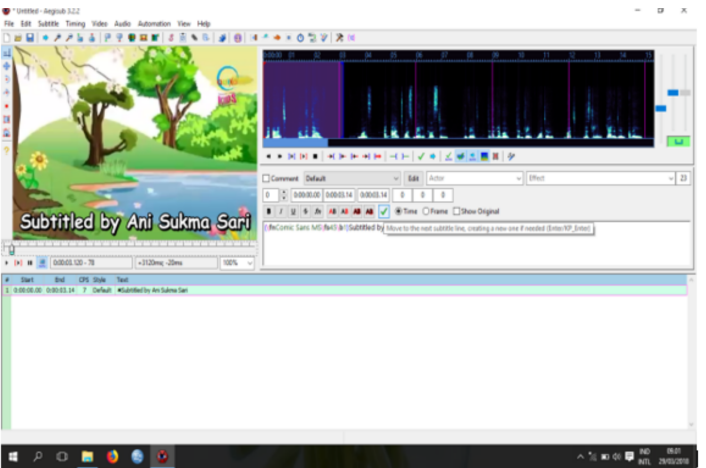

FIGURE 2 | The layout of the homebar used to move to the next subtitle line

\section{The Result of Expert Validation}

The proposed design of teaching media using video subtitle application was first consulted to an expert to test the validation. Having the expertise in Information and Communication Technologies (ICT), the expert was asked to give comments, feedback, and suggestion which are presented in the following discussion.

The expert stated that the application used to create video subtitle was relatively easy to work with since it only needs several procedures to successfully embed the subtitle into a video. Additionally, she also added that the application was readily accessible for the teachers. Overall, the expert stated that the application was helpful for beginners or teachers who wish to use video subtitle application.

\section{Try Out}

This ICT-based media development is created as a teaching medium to help teach listening skill to a prive junior high school in Indonesia. The video chosen as the medium for subtitling was a video of a fable. Fable was chosen because the research considered that it fits with the lesson plan. Closed captioning the video helps the students easily understand the story in the video and the structures of narrative text - orientation, complication, and resolution. This medium was developed by deploying two learning techniques; individual activity and group work. The steps in teaching the listening skill using subtitled video as the teaching media are as follows:

\section{Individual activity (Warming up)}

1. The teacher gives a paper containing a word to every student. The words are taken from the video,

2. The teacher asks the students to stand up and listen carefully to the video of a fable "the Ant and the Dove",

3. The students are allowed to sit down after they hear the word on their piece of paper,

4. After finishing hearing the story, the teacher shows the video of the fable (teacher need to prepare LCD in advance).
5. The students are then asked to check their words,

6. Lastly, the teacher asks the students to make a sentence from the word they have.

\section{Group work}

1. The teacher divides the students into several groups,

2. The teacher shows the chosen fable video "The Ant and the Dove" with the subtitle and ask the students to listen carefully and take important notes from the video,

3. After the video ends, the teacher gives an envelope to each group which contains some pictures and jumbled sentences related to the video,

4. The students are asked to arrange the pictures and jumbled sentences into a correct chronological order,

5. Finally, the teacher asks each group to correct the other groups' work together.

In the end, after giving individual activity and group discussion, the teacher shows slide presentation which contains explanation about the generic structure of narrative text (fable).

\section{Result of Implementation of Video Caption} as the Alternative Media to Teach Listening

Upon implementing the procedures in a listening class, findings are formulated as follows:

1. Students were more motivated in learning English especially listening skill. It was observed that the students really enjoyed the listening class and followed the lesson enthusiastically.

2. The teaching media allowed students to learn in an attractive way. It was shown by an improvement in memorization of new vocabularies supplied by the video.

3. This alternative media required the students to work both individually and in a group. As a result, they could experience a supportive learning atmosphere. It can be concluded that this alternative teaching media could really help teachers to build students' interaction.

4. Lastly, since the students were asked to correct their friends' work, it was found that students learned autonomy through the activities.

\section{The Final Product}

The research aimed to find an alternative teaching media which can help students learn English, especially the listening skill. Upon completing the experiment, the final product proposed is video subtitle embedded in a fable video. It is also important to note that integrating ICT into English learning by using an application to provide video subtitle is a very feasible alternative teachers can use to vary their teaching media. Teachers can design their own subtitle creatively with application such as Aegisub which is readily accessible and easy to operate. 


\section{DISCUSSION}

Upon concluding the experiment, this study found some beneficial results. First, the students are more enthusiastic in following and enjoying listening class. According to Danan (2004), subtitling can build learner's comprehension and lead to additional cognitive benefits such as greater depth of processing and understanding. It is because during listening class, they are watching the video while paying attention to the English subtitle.

It has been stated before that English video with subtitle helps students to develop their memorization of unknown or new words. As an example, learners can easily learn English vocabulary through watching a TV program with an English soundtrack and subtitles (Koolstra and Beentjes, 1999). In line with this, Wang (2012) showed that video materials with subtitles can serve as an effective alternative tool in teaching new L2 vocabulary since they combine visual and audio aids to develop the capacity of learner' working memory. To this, it can be firmly stated that video subtitle can potentially facilitate learners vocabulary acquisition without distraction since it also helps learners to notice new vocabularies (Wilson, 2002). To put it simply, subtitled videos visually and orally represent words and pictures and thus help students to activate their coding skill when processing pictures or words.

Next, it was also found that subtitled video may also boost students' active interaction during learning when it is combined with interactive teaching method. For instance, teachers are able to prepare variety of learning methods such as individual and group works. Following these, teachers can give learners exercise related to the subtitled video that the students can do independently or with their group members.

Last but not the least, the use of subtitled videos in listen-

\section{APPENDIX 1}

The Steps for operating Aegisub application for subtitling video:

1. Firstly, install this Aegisub application version 3-2-1 in your computer.

2. If you succeed to install this application. Then, it will appear in your window screen.

3. Click Aegisub icon twice, and then you will see this home screen.

4. In the home bar, click video and open video.

5. Choose your video that will be subtitled by using "Aegisub", and click open.

6. If the screen looks like this, it means your video is ready to be subtitled.

7. Clik this button, and set your font style and font size. Then, click OK.

8. Set the start of selected subtitles to current video frame by clicking this button. ing class also encourages learners' autonomy. As an example, in the learning process, the teacher can ask learners to closely look into a friend's work (for example, exercises to put jumbled sentences or pictures in logical or chronological order). The benefit of using subtitled video in learning English is that it helps the teachers creatively design and prepare various teaching methods with an innovative teaching media.

\section{CONCLUSION}

Innovation in teaching have yet reached its height. Teachers are truly recommended to be able to design their teaching media to be as creative as possible. Moreover, information and communication technology (ICT) is one of the best options in creating innovative teaching media since it provides teachers with novel and innovative ways of teaching.

This paper proposes an innovative teaching media employing video subtitle application Aegisub. Aegisub application provides an easy way to attach subtitle into a video. Hence, this paper proposes the procedures to prepare teaching media using Aegisub and also the steps to implement this teaching media in teaching listening.

It is expected that the students will be more motivated to learn English, especially listening skill. Last but not least, through this teaching media, it is hoped that students will be more active and engaged with the teaching and learning instructions.

\section{ACKNOWLEDGMENT}

This research was supported by English Education Study of Graduate Program of University of Islam Malang, Indonesia.

9. Type the subtitle in the box provided.

10. Play video starting on the position you want to add subtitle.

11. Pause the video playback where you want to end the subtitle.

12. Then, click this button to set end of selected subtitles.

13. Click this button in the home bar to move to the next subtitle line.

14. Repeat the same steps from 8 to 13 for adding subtitle until you arrive at the end of the subtitle.

15. Click file and save subtitle or you can use alternative button by clicking CTRL+S.

16. Save the subtitle file in the same folder where you save the video. Then, click save.

17. Then, make sure that the subtitle file and the video are in the same name in a folder.

18. Click open with the video player application you have such as GOM PLAYER or VLC.

19. Finally, you can play and enjoy the subtitled video to teach listening skill. 


\section{REFERENCES}

Baltova, I. (1999). Multisensory Language Teaching in a Multidimensional Curriculum: The Use of Authentic Bimodal Video in Core French. doi: 10.3138/cmlr.56. 1.31. https://dx.doi.org/10.3138/cmlr.56.1.31.

Bordonaro, K. (2014). The Intersection of Library Learning and Second-Language Learning. Theory and Practice.

Borg, W. R., Gall, J. P., and Gall, M. D. (2003). Educational Research: An Introduction Seventh Edition (United States: Pearson Education, inc).

Bruner, J. (1991). The Narrative Construction of Reality. doi: 10.1086/448619. https://dx.doi.org/10.1086/448619.

Danan, M. (2004). Reversed subtitling and dual coding theory. New directions for foreign language instruction. Language Learning 42, 497-527.

Dang, X. T. (2011). Factors influencing teachers' use of ICT in language teaching: A case study of Hanoi University (Vietnam).

Gernsbacher, M. A. (2015). Video Captions Benefit Everyone. Policy Insights from the Behavioral and Brain Sciences 2, 195-202. doi: 10.1177/2372732215602130.

Ghoneim, N. M. M. (2013). The Listening Comprehension Strategies Used by College Students to Cope with the Aural Problems in EFL Classes: An Analytical Study. doi: 10.5539/elt.v6n2p100. https://dx.doi.org/10.5539/elt.v6n2p100.

Knezek, G. and Christensen, R. (2002). Impact of New Information Technologies on Teachers and Students. Education and Information Technologies 7, 369-376. doi: 10.1023/a:1020921807131.
Koolstra, C. M. and Beentjes, J. W. J. (1999). Children's vocabulary acquisition in a foreign language through watching subtitled television programs at home. doi: 10.1007/bf02299476. https://dx.doi.org/10.1007/bf02299476.

Latief, M. A. (2015). Research methods on language learning: An introduction (UM Press).

Sari, A. and Sukma (2018). Construing students' perception on the use of information and communication technologies (ICTs) to ameliorate enthusiasm of literacy.

Wang, Y. C. (2012). Learning L2 Vocabulary with American TV Drama” From the Learner's Perspective. English Language Teaching 5, 217-225.

Wilson, C. C. (2002). Practical aspects of using video in the foreign language classroom. The TESL Journal 5.

Conflict of Interest Statement: The authors declare that the research was conducted in the absence of any commercial or financial relationships that could be construed as a potential conflict of interest.

Copyright (C) 2020 Mustofa and Sari. This is an open-access article distributed under the terms of the Creative Commons Attribution License (CC BY). The use, distribution or reproduction in other forums is permitted, provided the original author(s) and the copyright owner(s) are credited and that the original publication in this journal is cited, in accordance with accepted academic practice. No use, distribution or reproduction is permitted which does not comply with these terms. 